\title{
Rational Design of New Class of BH3-Mimetics As Inhibitors of the $\mathrm{BCl}-\mathrm{x}_{\mathrm{L}}$ Protein
}

\author{
Marta Pinto, ${ }^{+, \neq}$Maria del Mar Orzaez, ${ }^{\S}$ Laura Delgado-Soler, ${ }^{\dagger}$ Juan J. Perez, ${ }^{\ddagger}$ and Jaime Rubio-Martinez ${ }^{*,+}$ \\ ${ }^{\dagger}$ Department of Physical Chemistry, University of Barcelona (UB), and Instituto de Química Teórica y Computacional (IQTCUB), \\ Barcelona, Spain \\ ${ }^{\ddagger}$ Department of Chemical Engineering, Polytechnic University of Catalonia (UPC), ETSEIB, Catalonia, Spain \\ ${ }^{\S}$ Department of Medicinal Chemistry, Centro de Investigación Príncipe Felipe, and Instituto de Biomedicina de Valencia, CSIC, \\ Valencia, Spain
}

Supporting Information

ABSTRACT: The Bcl-2 family of proteins plays an important role in the intrinsic pathway of cell apoptosis. Overexpression of prosurvival members of this family of proteins is often associated with the development of many types of cancer and confers resistance against conventional therapeutic treatments. Accordingly, antagonism of its protective function has emerged as an encouraging anticancer strategy. In the present work, we use a pharmacophore for describing interaction between the $\mathrm{BH} 3$ domain of different pro-apoptotic members and the pro-survival protein $\mathrm{Bcl}-\mathrm{x}_{\mathrm{L}}$ in order

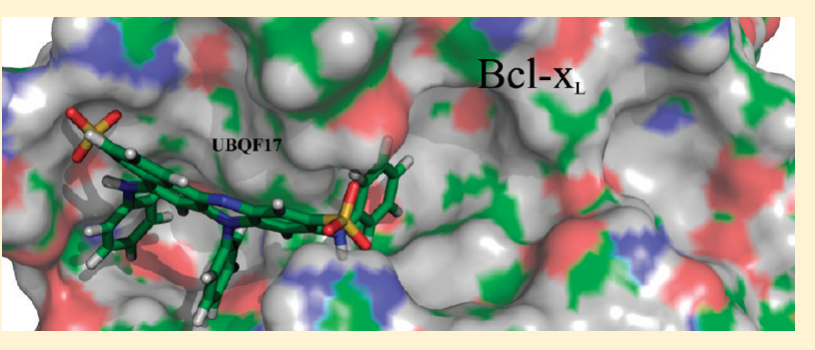
to identify new lead compounds. In the strategy followed in the present work, the pharmacophore was derived from molecular dynamics studies of different $\mathrm{Bcl}-\mathrm{x}_{\mathrm{L}} / \mathrm{BH} 3$ complexes. This pharmacophore was later used as query for 3D database screening. Hits obtained from the search were computationally assessed, and a subset proposed for in vitro testing. Two of the 15 compounds assayed were found able to disrupt the $\mathrm{Bcl}-\mathrm{x}_{\mathrm{L}} / \mathrm{Bak}(\mathrm{BH} 3)$ complex with $\mathrm{IC}_{50}$ values in the lower micromolar range. Finally, docking studies were performed to explore the binding mode of these compounds to $\mathrm{Bcl}-\mathrm{x}_{\mathrm{L}}$ for further modifications.

\section{INTRODUCTION}

Apoptosis or programmed cell death is essential during embryogenesis and cellular homeostasis and plays an important role in the defense against pathogens. Defects in apoptotic pathways contribute to a number of human diseases, such as cancer and autoimmune or neurodegenerative diseases. ${ }^{1,2}$ Apoptosis is orchestrated by a group of intracellular cysteinyl aspartate proteases called caspases, ${ }^{3}$ synthesized as inactive zymogens that are activated through two major interconnected pathways: ${ }^{4,5}$ an extrinsic pathway, activated by ligation of the so-called cell death receptors, and an intrinsic pathway, caused by perturbation of the mitochondria and regulated by the $\mathrm{Bcl}-2$ family of proteins, which is the focus of the present report.

To date, at least $20 \mathrm{Bcl}-2$ family members have been identified in mammalian cells, including proteins that promote apoptosis (hereafter referred as pro-apoptotic) and those that prevent it (hereafter referred as anti-apoptotic). All these proteins are characterized by exhibiting at least one of the four highly conserved so-called Bcl-2 homology domains (hereafter referred to as $\mathrm{BH} 1-\mathrm{BH} 4)$, that are useful to classify these proteins into three groups: (1) proteins, such as Bcl-2, Bcl- $x_{\mathrm{L}}$, Mcl-1, and Bfl-1, all of which exhibit anticell death and conserve the four highly conserved domains $\mathrm{BH} 1-\mathrm{BH} 4$; (2) proapoptotic multidomain members, such as Bax, Bak, or Bok, which share sequence homology in the $\mathrm{BH} 1, \mathrm{BH} 2$, and $\mathrm{BH} 3$ domains, and finally, (3) the BH3-only proteins such as Bid, Bim, Bmf, Bik, Noxa, Puma, $\mathrm{Bad}$, and Hrk, which contain only a $\mathrm{BH} 3$ domain essential for their killing function. ${ }^{6-10}$

The relative amount between pro- and anti-apoptotic proteins determines the susceptibility of the cell to apoptosis. Indeed, in many tumor cells $\mathrm{Bcl}-\mathrm{x}_{\mathrm{L}}$ is overexpressed, impairing cell capability to undergo apoptosis and showing resistance to conventional anticancer therapies. Therefore, inhibition of this protein or reduction of its level modulates the drug resistance of tumor cells by increasing their susceptibility to undergo apoptosis.

The anticell death activity of the anti-apoptotic proteins is due, at least in part, to their dimerization with proapoptotic members of the Bcl-2 family. Structural studies reveal that, in response to prosurvival stimuli, anti-apoptotic proteins undergo a conformational change that leads to the formation of a hydrophobic groove on their surface where the amphipathic $\alpha$-helical BH3 domain of the proapoptotic protein binds. ${ }^{11-14}$ By this process overexpressed prosurvival proteins sequester pro-apoptotic ones compromising cell capability to undergo apoptosis. Interestingly, the $\mathrm{BH} 3$ domain fragments of pro-apoptotic proteins exhibit high affinity for the prosurvival proteins and play the role of antagonist of these proteins. Indeed, binding of these peptides to the pro-survival proteins has

Received: December 21, 2010

Published: April 29, 2011 
<smiles>CCOC(=O)C(C(=O)OCC)C1c2cc(F)ccc2OC(C)C1C(=O)OCC</smiles>

HA14-1

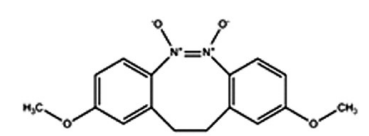

Compound 6

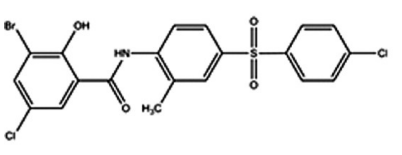

BH3I-2

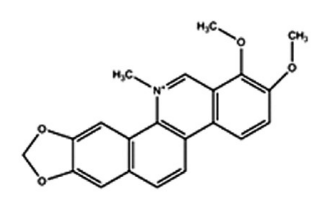

Chelerythrine

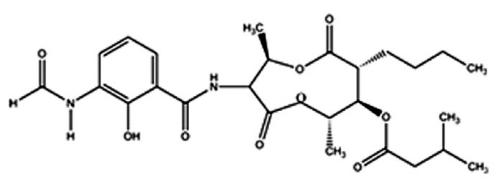

Antimycin-A<smiles>C=C1SC(=Cc2ccc(C)cc2)C(=O)C1C(C(=O)O)C(C)C</smiles>

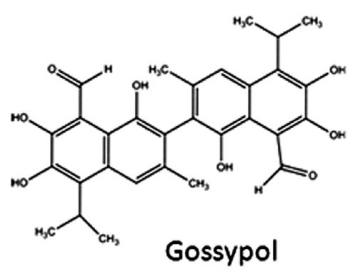

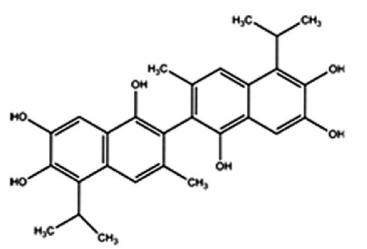

Apogossypol

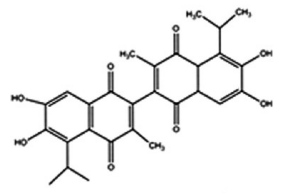

Apogossypolone<smiles>CC(C)C1CCCC1CC1CC(C)C(C)C(C)C1CC1CCC(C2(C)CCCC2C(C)C)CC1</smiles>

TW37

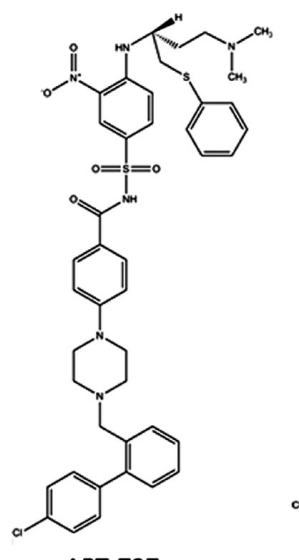

ABT-737

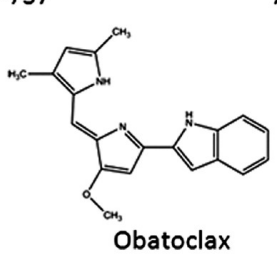

$73 R$<smiles>CN(C)C(=O)c1ccc(N)cc1</smiles>

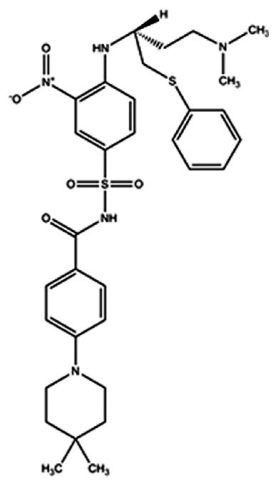

ABT-263

Figure 1. Structures of some compounds reported as Bcl-2 and/or Bcl- $\mathrm{x}_{\mathrm{L}}$ inhibitors. ${ }^{21-32}$

been shown to promote apoptosis in different cell lines. ${ }^{15-20}$ However, in order to surmount the difficulties associated to the use of peptides as therapeutic agents, the design of small molecule mimics of the $\mathrm{BH} 3$ domain of the pro-apoptotic members of the Bcl-2 family can be considered as an appealing strategy for designing new anticancer agents.

Following different strategies, several groups have reported in the last years the discovery of small-molecule antagonists of Bcl-2 or $\mathrm{Bcl}-\mathrm{x}_{\mathrm{L}}$ (see Figure 1 and references therein). In this direction, we report in the present work the results of a pharmacophoredirected virtual screening approach for the discovery of small molecules, antagonists of the $\mathrm{Bcl}-\mathrm{x}_{\mathrm{L}}$ protein. Suitability of the identified hits was assessed using the in-house docking program DockDyn (DOCKing using DYNamic information), a docking code based on the fulfilment of a recognition pharmacophore derived from molecular dynamics (MD) simulations. ${ }^{36}$ Following this procedure, 15 compounds were selected for in vitro testing. Two of them competed with $\mathrm{Bak}(\mathrm{BH} 3)$ for binding to $\mathrm{Bcl}-\mathrm{x}_{\mathrm{L}}$ with $\mathrm{IC}_{50}$ values in the low micromolar range. Characterization of the binding mode of these compounds to $\mathrm{Bcl}-\mathrm{x}_{\mathrm{L}}$ for further optimization was performed through docking studies using the Glide v4.0 $0^{37}$ module of the Maestro v8.5 suite of programs. ${ }^{38}$

\section{THEORETICAL CALCULATIONS}

Pharmacophore Definition. In order to identify the stereochemical features that characterize the binding of different hexadecapeptides derived from the $\mathrm{BH} 3$ domain of pro-apoptotic proteins (hereafter referred to as $\mathrm{X}(16 \mathrm{BH} 3)$, where $\mathrm{X}$ represents Bak, Bax, $\mathrm{Bid}$, and $\mathrm{Hrk}$ ) to $\mathrm{Bcl}-\mathrm{x}_{\mathrm{L}}, \mathrm{MD}$ simulations of different $\mathrm{Bcl}-\mathrm{x}_{\mathrm{L}} /$ $\mathrm{X}(16 \mathrm{BH} 3)$ complexes were performed ${ }^{36}$ using the NMR structure of the Bcl- $x_{\mathrm{L}} / \mathrm{Bak}(16 \mathrm{BH} 3)$ complex (entry 1BXL of the Protein Data Bank) ${ }^{11}$ as a template. Analysis of these trajectories permitted us to identify four common pharmacophoric points that characterize the recognition features of the $\mathrm{BH} 3$ domains to $\mathrm{Bcl}-\mathrm{x}_{\mathrm{L}}$. These chemical features, defined on the ligand, include: two hydrophobic groups (HYD1 and HYD2) and two hydrogen-bond acceptors (HBA1 and HBA2) as shown in Figure 2. To determine the spatial arrangement of these pharmacophoric groups, each of them was represented by a single point. For hydrophobic groups, the point was located at the center of mass of the side chain. For hydrogenbond acceptor groups, the center of the oxygen-oxygen carboxylic distance was considered as pharmacophoric point. This reference pharmacophore was defined using the maximum and the minimum distance values adopted by each pair of pharmacophoric points along the last $500 \mathrm{ps}$ of the $\mathrm{MD}$ trajectory over the four $\mathrm{Bcl}-\mathrm{x}_{\mathrm{L}} /$ $\mathrm{X}(16 \mathrm{BH} 3)$ complexes.

In Silico Database Screening and Selection. Hits were identified according to their fulfilment of a pharmacophore query. Different three-dimensional (3D) databases, including Available Chemicals Directory (ACD, 266.812 compounds), National Cancer Institute (NCI, 98.868 compounds), Maybridge (MB, 47.045 compounds), and Derwent World Drug (DWD, 48.405 compounds) were screened using the Catalyst package (Catalyst, Accelrys Inc., San Diego, CA) with default parameters. Based on the previously defined pharmacophore, four different queries were 


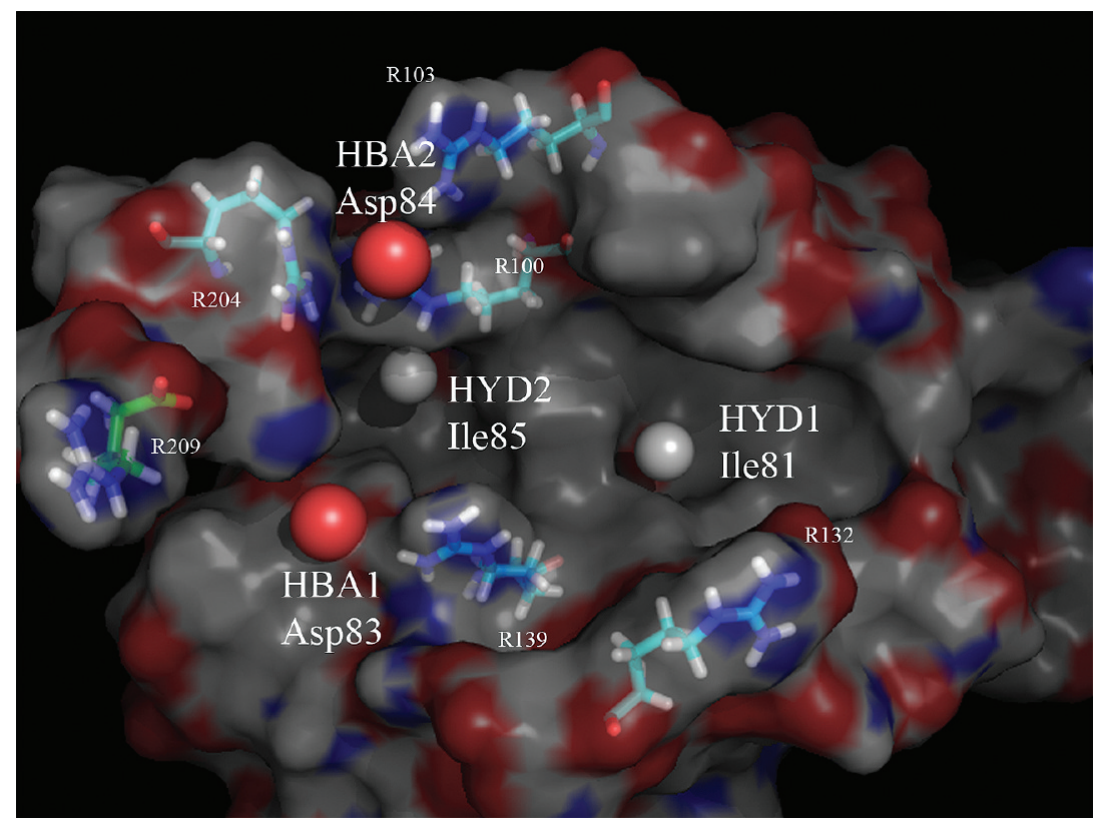

Figure 2. Spatial rearrangement of the pharmacophoric groups found for the $\mathrm{Bcl}-\mathrm{x}_{\mathrm{L}}$ protein. The model contains two hydrophobic groups (HYD1 and HYD2) and two hydrogen-bond acceptors (HBA1 and HBA2). In the complex Bcl- $\mathrm{x}_{\mathrm{L}} / \mathrm{Bak}(72-87)$, the hydrophobic groups map the residues Ile ${ }^{81}$ and $\mathrm{Ile}^{85}$ of the hexadecapeptide. The two hydrogen-bond acceptors match the residues Asp ${ }^{83}$ and Asp ${ }^{84}$, respectively. ${ }^{36}$

used for database searching: a four-point pharmacophore including HYD1, HYD2, HBA1, and HBA2 and two three-point pharmacophores: HYD1, HYD2, and HBA1 and HYD1, HYD2, and HBA2, labeled as phar4, phar31 and phar32, respectively. Compounds matching at least one of the queries were stored for further analysis.

Hits identified after screening the 3D databases were filtered according to their drug-likeness properties, and only those with a molecular weight $(\mathrm{MW}) \leq 800 \mathrm{Da}$ were retained. Next, all selected hits were further assessed using an in-house pharmacophore-based docking program DockDyn.

Docking Studies. DockDyn is an in-house docking program ${ }^{36}$ based on pharmacophore fulfilment and steric features of the binding site. DockDyn works in four steps: (1) assignment of pharmacophoric features to each of the ligands to be docked; (2) generation of ligand conformations; (3) discard of those conformations that do not match the pharmacophoric hypothesis; and (4) docking and evaluation of the selected conformations into the target binding site in order to evaluate their steric complementarity. In the first step, DockDyn automatically assigns the pharmacophoric features to the ligand. These features include HBA, hydrogen-bond donors $(\mathrm{HBD})$, positive charges $(\mathrm{Q}+)$, negative charges $(\mathrm{Q}-$ ), hydrophobic moieties (HYD) and aromatic rings (AR), although this list can be easily modified. Next, the program identifies all the rotatable bonds of the ligand and generates new conformations by rotation around these bonds. The rotational angle increment depends on the number of total rotatable bonds and on the type of bond. It is computed so that the number of generated conformations remains equal or lower than a predetermined value (default value is $2 \times 10^{5}$ ). Rotations are performed using the quaternions formalism. Intramolecular clashes are taken into account using the criteria that two atoms are in steric clash if their distance is lower than the sum of their respective van der Waals radii with some tolerance. At this point, the program checks if the pharmacophoric features of any of the conformations generated match the pharmacophoric hypothesis. If it is true, then the program superimposes each of the pharmacophoric features of a given conformation to the pharmacophoric hypothesis points defined into the binding site of the protein. Superposition is done by minimizing the root-mean-square standard deviation (RMSD) between the pharmacophoric points of the ligand and those of the reference pharmacophore. The RMSD value is used as a scoring function to rank the compounds. Conformations with van der Waals clashes were discarded. The criterion used is the same as explained before for the intramolecular clashes but using another tolerance factor in order to introduce some degree of protein flexibility. If steric clash exists, then the program allows small translations of the center of mass of the ligand into the binding site of the protein to avoid it. In order to reduce the computational cost, only residues of the protein with at least one atom within a cutoff distance of $14 \AA$ from the pharmacophoric reference points are included in the calculation.

Glide. To avoid any possible bias introduced by our pharmacophore-directed program, docking studies were also carried out with Glide, ${ }^{37}$ a general nonpharmacophore-dependent docking program developed by Schrödinger. ${ }^{38}$ Its choice was based on its ability to model, through the Induced Fit Docking protocol, ${ }^{39}$ the conformational changes induced in the protein by ligand binding. This procedure works in four sequential steps: (1) use of a softened van der Waals potential to dock the ligand into the rigid receptor and to generate an initial ensemble of poses; (2) protein sampling for each ligand pose by using Prime v1.6; ${ }^{40}$ (3) redocking of the ligands into the best ranked induced fit structures; and (4) scoring of the new ligand poses by using a combination of the Prime energy and Glide XP score.

Initial coordinates of the $\mathrm{Bcl}-\mathrm{x}_{\mathrm{L}}$ protein were taken from the NMR complex Bcl- $x_{L} / \operatorname{Bak}(72-87)$ (PDB: 1BXL). ${ }^{11}$ Terminal residues of the protein were manually charged. Bond orders and protonation states of the protein were automatically adjusted by using the Protein Preparation Wizard workflow included in the 
Maestro v.8.5 software package. Ligand structures were manually adjusted using the Builder module. Conformers and tautomers were generated by using the LigPrep module included in the Maestro package. The binding site of the $\mathrm{Bcl}-\mathrm{x}_{\mathrm{L}}$ protein was defined on the Bak peptide, positioning the grid box used for the docking stage on its center. Sizes for the inner and the outer boxes were automatically defined by default values. No residues were mutated to alanine because there were no residues blocking the binding site. In order to reduce steric clashes in the rigid docking stage, a scaling factor of 0.5 in the van der Waals radii was used for all atoms of the binding pocket. Prime protein refinement was carried out for the first 20 poses obtained after initial docking. It was performed for protein residues located within $5 \AA$ of the ligand. Finally, Glide redocking was carried out using the $\mathrm{XP}$ default parameters on the protein structures having energies in the range of $0-20 \mathrm{kcal} / \mathrm{mol}$ with respect to the lowest energy value produced by Prime.

Energy Minimization. In order to adapt the docking structures to the new force field calculations, the most probable complexes produced by Glide were minimized by using the AMBER v.9 program package. ${ }^{41}$ The $\mathrm{ff} 3^{42}$ and the GAFF force fields ${ }^{43}$ were used for the protein and the ligands, respectively. All starting systems were solvated by adding a cubic box of explicit TIP3P water molecules ${ }^{44}$ with a minimum distance between the protein and the edge of the box of $10 \AA$. Waters closer than $1.8 \AA$ to any molecule or protein atom were removed. Finally, the systems were neutralized with the necessary counterions. Simulations were performed using periodic boundary conditions with the long-range electrostatic interactions calculated by means of the particle mesh Ewald method. ${ }^{45}$ A cutoff distance of $10 \AA$ was chosen to compute nonbonded interactions.

The minimizations were carried out in a multistep procedure. In the three first steps, 1000 steps of steepest descent followed by 4000 steps of conjugate gradient were done restraining the protein backbone with a harmonic potential of force constant of 50,5 , and $0.5 \mathrm{kcal} / \mathrm{mol}^{2} \AA^{2}$, respectively. Finally, complexes were minimized without any restriction until the root-meansquare gradient of the potential energy was $\leq 0.001 \mathrm{kcal} / \mathrm{mol}$.

Molecular Dynamics. Minimized complexes were used as starting point for the MD simulations. The MD simulations were performed at a constant temperature of $300 \mathrm{~K}$ by coupling the system to a thermal bath using Berendsen's algorithm, ${ }^{46}$ as implemented in AMBER9, ${ }^{41}$ with a time coupling constant of 0.2 ps. The SHAKE procedure ${ }^{47}$ was used to constrain all bonds involving hydrogen atoms. The integration time was set to $2 \mathrm{fs}$ using the default value for the update of the nearest-neighbor list. A cutoff of $9 \AA$ for nonbonded interactions was used.

$\mathrm{MD}$ simulations started by heating the minimized structures to $300 \mathrm{~K}$ under constant volume and temperature conditions $(\mathrm{N}, \mathrm{V}, \mathrm{T})$ at a constant rate of $30 \mathrm{~K} / 10 \mathrm{ps}$. Then, $100 \mathrm{ps}$ of constant pressure and temperature $(\mathrm{N}, \mathrm{P}, \mathrm{T})$ allowed the system to reach the proper density. Finally, a 6 ns dynamics calculation was performed in the canonical ensemble $(\mathrm{N}, \mathrm{V}, \mathrm{T})$ with a constant temperature of $300 \mathrm{~K}$.

MM-PB/GBSA Approach. Binding free energies of the minimized most-populated docked complexes were calculated using the molecular mechanics Poisson-Boltzmann/generalized Born surface area (MM-PB/GBSA) approach ${ }^{48}$ implemented in the AMBER v.9.0 program package. This algorithm evaluates the binding free energy as

$$
\Delta G_{\text {binding }}=\Delta G_{\text {gas }}+\Delta G_{\text {solv }}-T \Delta S
$$

where $\Delta G_{\text {gas }}$ is the $\mathrm{MM}$ interaction energy between protein and ligand (sum of the nonbonded electrostatic (Coulombic), van der Waals
(Lennard-Jones), and internal energy contributions (bonds, angles and dihedrals) in vacuo), $\Delta G_{\text {solv }}$ is the solvation free energy, and $-T \Delta S$ is the conformational entropy change. $\Delta G_{\text {solv }}$ can be expressed as the sum of an electrostatic $\left(\Delta G_{\text {solv,elec }}\right)$ component and a nonpolar $\left(\Delta G_{\mathrm{np}}\right)$ component:

$$
\Delta G_{\text {solv }}=\Delta G_{\text {solv, elec }}+\Delta G_{\text {np }}
$$

The electrostatic contribution to the solvation free energy was computed solving the PB equation or using the GB method. ${ }^{49}$ Both methods assume that the nonpolar contribution is proportional to the solvent accessible surface area (SASA). It is calculated as $\Delta G_{\mathrm{np}}=$ $\gamma$ SASA $+b$, with $\gamma=0.00542 \mathrm{kcal} / \mathrm{mol} \AA^{2}$ and $b=0.92 \mathrm{kcal} / \mathrm{mol}$ for $\mathrm{PB}$ and $\gamma=0.0072 \mathrm{kcal} / \mathrm{mol} \AA^{2}$ and $b=0 \mathrm{kcal} / \mathrm{mol}$ for GB calculations, employing the Linear Combinations of Pairwise Overlaps (LCPO) method. ${ }^{50}$ Values of the internal and external dielectric constants were 1 and 80, respectively. Entropic contributions were neglected.

To estimate the contribution of each residue of the $\mathrm{Bcl}-\mathrm{x}_{\mathrm{L}}$ protein to the binding free energy, the MM-GBSA per residue protocol $^{51}$ was applied. This methodology describes not only the interactions in vacuo but also adds the solvation contribution to the final binding free energy. In this approach all pairwise interactions are equally distributed between the interacting atoms.

\section{EXPERIMENTAL SECTION}

Inhibition Assays. Fluorescence polarization measurements were made in a Victor2 V 1420 Multilabel HTS Counter. A $60 \mathrm{nM}$ solution of $5^{\prime}-6^{\prime}$-carboxyfluorescein (CF) labeled peptide derived from the $\mathrm{BH} 3$ domain of Bak (CF-Bak(BH3); CF-GQVGRQLAIIGKKINR-NH $\left.{ }_{2} ;{ }^{52} \lambda_{\text {exc }}=480 \mathrm{~nm} ; \lambda_{\text {em }}=535 \mathrm{~nm}\right)$ in buffer A (total reaction volume was $200 \mu \mathrm{L}$ ) was titrated with concentrated $\mathrm{Bcl}-\mathrm{x}_{\mathrm{L}}$ protein solutions in the presence and absence of compounds. ${ }^{53}$ Data were recorded by using a Wallac 1420 Workstation software.

$\boldsymbol{\beta}$-Lactamase Assays. $\beta$-Lactamase assays were performed using $2 \mathrm{nM}$ enzyme. Compounds were preincubated with the enzyme for $15 \mathrm{~min}$ at room temperature. After incubation, $200 \mu \mathrm{M}$ of a $\beta$-lactamase-labile, chromogenic cephalosporin reagent (CENTA), was added to the mixture. The reaction was monitored by measuring the increase in absorbance at $405 \mathrm{~nm}$ produced by the hydrolysis of the $\beta$-lactam ring.

\section{RESULTS AND DISCUSSION}

Virtual screening has been successfully used by diverse groups to identify small molecule antagonists of the $\mathrm{Bcl}-\mathrm{x}_{\mathrm{L}}$ or $\mathrm{Bcl}-2$ proteins. Wang and co-workers used a virtual screening process to identify compound HA14-1 (Figure 1), a nonpeptidic and cell permeable antagonist of Bcl-2. ${ }^{17}$ High-throughput virtual screening was also used by Petros and co-workers to identify new antagonists of the $\mathrm{Bcl}-2$ protein. ${ }^{13}$ One of them inhibits cell growth with an $\mathrm{IC}_{50}$ of $4 \mu \mathrm{M}$ and induces apoptosis in cancer cells. In both studies, the 3D structure of the Bcl-2 protein was obtained by homology modeling. The program DOCK was then used to screen a molecular database against the binding site of the protein. Recently, a virtual screening using a receptor-based pharmacophore has been used to discover a new low-micromolar Bcl-2 inhibitor. ${ }^{54}$

The novelty of the results reported in the present work regards the use of an average pharmacophore derived from $\mathrm{MD}$ studies of the $\mathrm{Bcl}-\mathrm{x}_{\mathrm{L}} / \mathrm{X}(16 \mathrm{BH} 3)$ complexes, not only as a query to screen several molecular databases but also for docking the selected 
<smiles></smiles>

UBQF14 $7 \pm 2 \mu \mathrm{M}$

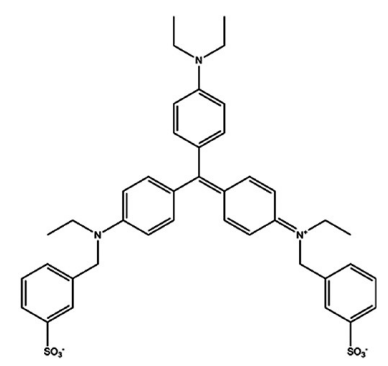

UBQF17

$8 \pm 1 \mu \mathrm{M}$<smiles>COc1cc([N+](=O)[O-])c(O)cc1C=NC(=NNc1cc(O)c(O)cc1OC)C(=O)Nc1ccccc1</smiles>

Figure 3. $\mathrm{IC}_{50}$ values for each of the tested compounds. These values, obtained by fluorescence polarization assays, represent the mean \pm SD of three different measurements.

compounds by matching them to this averaged pharmacophore model positioned into the binding site of the protein.

As has been explained in the Theoretical Calculations Section, three different queries phar4, phar31, and phar32 based on the averaged pharmacophore (Figure 2) were used to screen the four databases. After rejecting hits with a $\mathrm{MW} \leq 800 \mathrm{Da}$, unusual bonds, or several fragments, the ACD database produced 63 hits using query phar4 and 114 hits using phar31 and phar32. Likewise, the NCI database yielded 42 and 210 hits for the fourand three-point queries, respectively. No hits were obtained from the other two remaining databases.

Although molecules with MW greater than $500 \mathrm{Da}$ are not usually regarded as drug-like compounds, our own experience indicates that sometimes molecules with MW between 500 and $800 \mathrm{Da}$ properly fulfill the pharmacophore requirements and show a good interaction profile. However, they also have some noninteracting groups which are solvent exposed. Deletions of these groups generate small molecules that retain interaction points and that may exist in other databases or that can be synthesized in further studies. So, in order to cover these possibilities, we decided to include compounds having a MW $\leq 800$ Da.

In a further step, the in-house pharmacophore-based docking program DockDyn, described in the Docking Studies Section, was used to filter compounds for further testing. From the 429 initial hits docked into the binding site of $\mathrm{Bcl}-\mathrm{x}_{\mathrm{L}}$, only those with a RMSD $<2.5 \AA$ for the four-point query and $<1.5 \AA$ for the threepoint query, respectively, were considered for in vitro testing. Accordingly, the final set consisted of 29 compounds, 20 of them from the NCI database and 9 from the ACD database. However, two of the 20 compounds found in the NCI list were the same molecule, and one of them appeared in both databases. So, the final set was reduced to 27 compounds. Of them, the 19 from

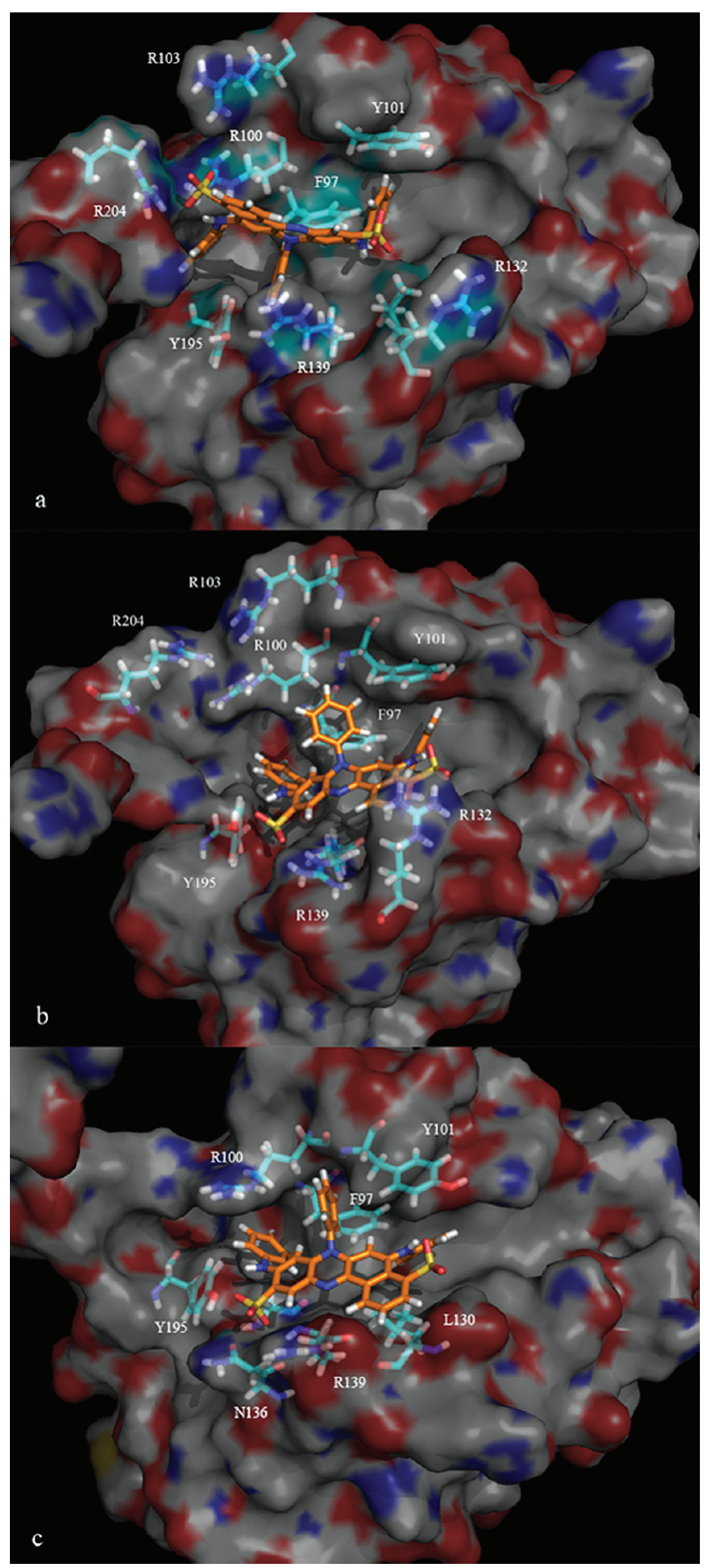

Figure 4. Best docking pose obtained for the UBQF14 compound bound to Bcl- $\mathrm{x}_{\mathrm{L}}$ using: (a) the DockDyn program (phar32), (b) the Glide program (pose1), and (c) after $6 \mathrm{~ns}$ of $\mathrm{MD}$ using (b) structure as starting point.

the NCI were requested but finally only seven were received. Likewise eight ACD's compounds were purchased.

The binding affinity of the acquired 15 compounds to $\mathrm{Bcl}-\mathrm{x}_{\mathrm{L}}$ was determined in vitro using a competitive fluorescence polarization assay. For this assay, 5-carboxyfluorecein was coupled to the $\mathrm{N}$-terminus of the Bak peptide (CF-Bak(BH3)). This fluorescent 


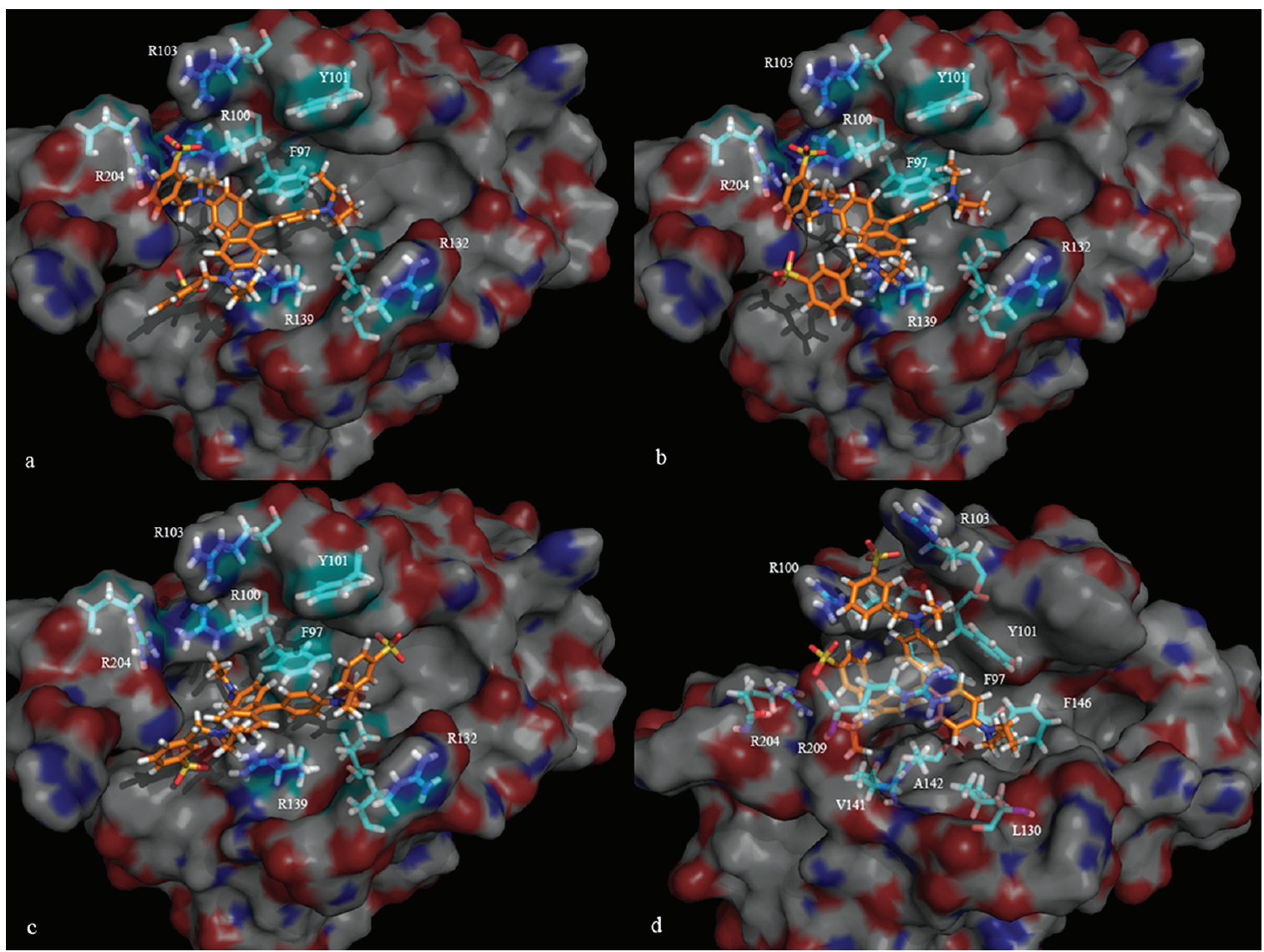

Figure 5. Best docking pose obtained for the UBQF17 compound bound to Bcl- $x_{\mathrm{L}}$ using: (a) the DockDyn program (phar4), (b) the DockDyn program (phar32), (c) the DockDyn program (phar31), and (d) the Glide program (pose10) after 6 ns of MD.

analogue binds to $\mathrm{Bcl}-\mathrm{x}_{\mathrm{L}}$ with high affinity (dissociation constant $\left.K_{\mathrm{D}}=2 \mu \mathrm{M}\right)$. Nonfluorescent Bak(BH3) peptide ${ }^{24}$ was used as positive control. The binding affinity of each compound for $\mathrm{Bcl}-\mathrm{x}_{\mathrm{L}}$ was evaluated by determining its ability to compete with CF$\mathrm{Bak}(\mathrm{BH} 3)$ for $\mathrm{Bcl}-\mathrm{x}_{\mathrm{L}}$ binding. Initially, all compounds were analyzed at a fixed concentration, and the most active were selected for subsequent analysis and $\mathrm{IC}_{50}$ values determination. Among the 15 compounds tested, three of them were able to displace CF$\mathrm{Bak}(\mathrm{BH} 3)$ from Bcl- $\mathrm{x}_{\mathrm{L}}$ (See Figure 3 and Figure S1, Supporting Information). Compounds UBQF-14 and UBQF-17 showed the most potent activity with $\mathrm{IC}_{50}$ values of $8 \mu \mathrm{M}$ (dose-response graphs for these compounds are included in Figure S2, Supporting Information).

To overcome the problems related to the target promiscuity of UBQF-14 and UBQF-17, they were tested in a completely unrelated enzymatic inhibition assay as previously described. ${ }^{55}$ The ability of these compounds to inhibit the $\beta$-lactamase activity was measured at different concentrations (see Figure S3, Supporting Information). In the case of UBQF-17, no inhibition was observed at concentrations 10 -fold higher than the $\mathrm{IC}_{50}$ of the compound. The compound UBQF-14 did not show relevant $\beta$-lactamase inhibition activity at concentrations up to $25 \mu \mathrm{M}$, but it clearly increased at higher concentrations. However, since the $\mathrm{IC}_{50}$ calculated for UBQF-14 is $7 \mu \mathrm{M}$, the possible unspecific inhibition may not affect the results observed for $\mathrm{Bcl}-\mathrm{x}_{\mathrm{L}}$.

In order to elucidate the most probable binding mode of UBQF-14 and UBQF-17 compounds to $\mathrm{Bcl}-\mathrm{x}_{\mathrm{L}}$ for further optimization, docking studies using the Glide Induced Fit
Table 1. Mean Values of the MM-PBSA and MM-GBSA Binding Free Energy Terms in $\mathrm{kcal} / \mathrm{mol}$ for the $\mathrm{Bcl}-\mathrm{x}_{\mathrm{L}} /$ UBQF14 and Bcl- $x_{\mathrm{L}} / \mathrm{UBQF} 17$ Complexes for the Last 2 ns of the MD Trajectories ${ }^{a}$

$\begin{array}{ccccccc}\text { compound } & \text { method } & \Delta G_{\text {total }} & \Delta G_{\text {vdW }} & \Delta G_{\text {elec }} & \Delta G_{\text {np }} & \Delta G_{\text {solv,elec }} \\ \text { UBQF14 } & \text { PB } & -33.8 & & & -6.5 & -90.8 \\ & \text { GB } & -31.8 & -50.1 & 113.7 & -5.1 & -90.2 \\ \text { UBQF17 } & \text { PB } & -47.6 & & & -8.8 & -1.8 \\ & \text { GB } & -44.3 & -67.4 & 30.4 & -7.3 & 0.0\end{array}$

${ }^{a} \Delta G_{\mathrm{vdW}}$ and $\Delta G_{\text {elec }}$ represent the nonbonded electrostatic (Coulombic) and van der Waals (Lennard-Jones) MM interaction energy. $\Delta G_{\mathrm{np}}$ and $\Delta G_{\text {solv,elec }}$ are the nonpolar and electrostatic components of the solvation free energy, respectively.

Docking Protocol (IFD) and the DockDyn procedures were performed. Thus, in order to compare both procedures and to avoid unreasonable ligand conformations, the best poses generated by each program were selected for $\mathrm{MD}$ refinement and further rescoring using the MM-PB/GBSA approach.

For this purpose, poses generated with the Glide IFD protocol were classified according to the binding pattern. Only the topranked pose of the most populated binding modes (3 for UBQF14 and 11 for UBQF17) were selected. In the case of the DockDyn program, selection of the best poses was based on the RMSD value between their pharmacophoric groups and the pharmacophore query for which they have been proposed. For 


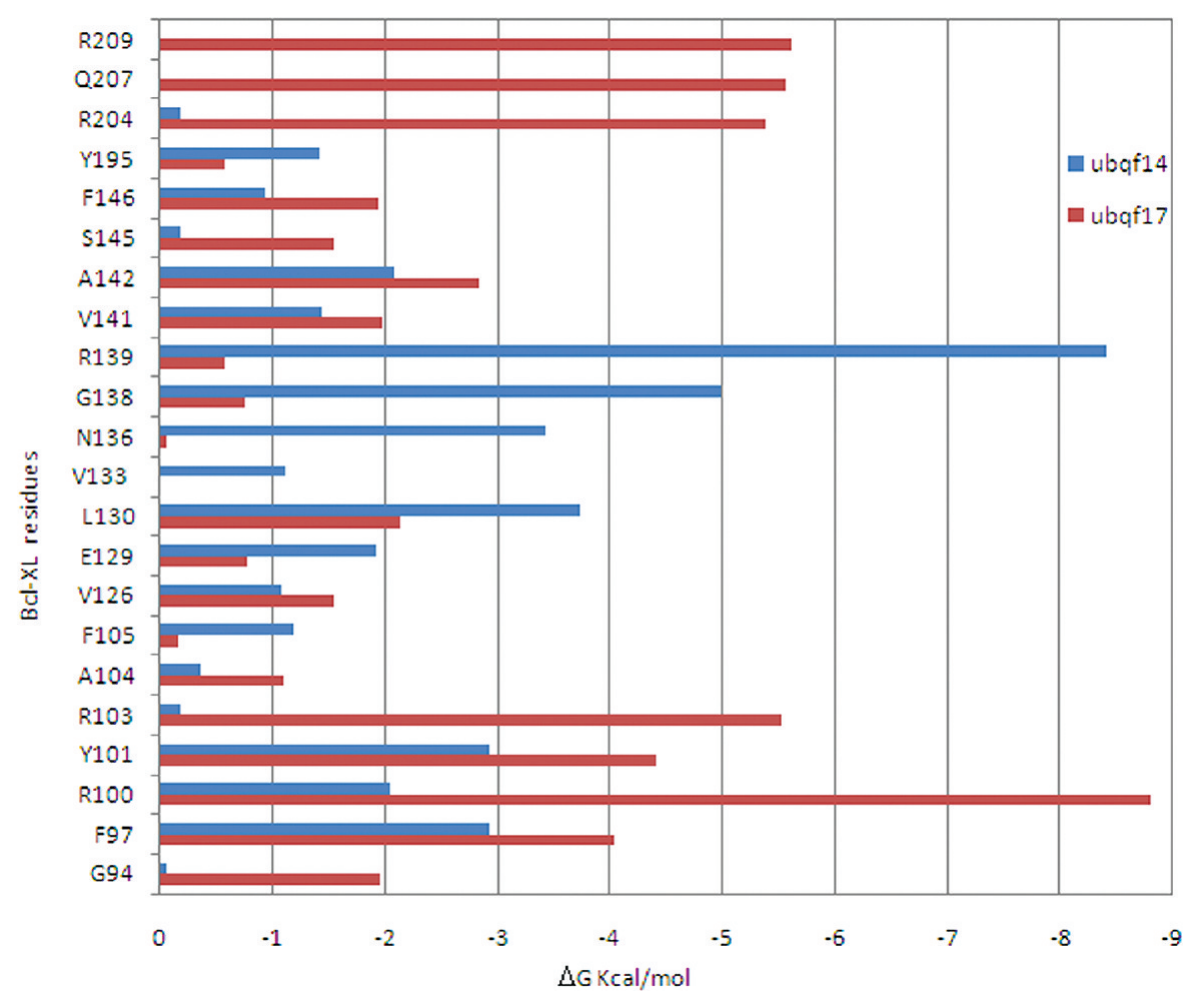

Figure 6. Residues of $\mathrm{Bcl}-\mathrm{x}_{\mathrm{L}}$ that contribute more than $1.0 \mathrm{kcal} / \mathrm{mol}$ to the binding free energy of the complexes.

this selection, only poses having a RMSD $\leq 2.5 \AA$ for phar 4 and $\leq 1.5 \AA$ for phar31 and phar32 were considered. So, for UBQF14, the DockDyn protocol generated a pose with a $\mathrm{RMSD}=0.88 \AA$ using the three-point pharmacophore query phar32. No poses were obtained below the predefined RMSD value for the other two remaining queries. For the UBQF17 compound, all three pharmacophore queries generated poses with acceptable RMSD values of $0.63,0.30$, and $0.41 \AA$ for phar4, phar31, and phar32, respectively. Accordingly, a total of 19 complexes (four for UBQF14 and 15 for UBQF 19) were considered for further analysis.

Figure $4 \mathrm{a}$ shows the pose generated using DockDyn for UBQF14. As can be seen, the aromatic rings of this compound fit into the hydrophobic pockets of the $\mathrm{Bcl}-\mathrm{x}_{\mathrm{L}}$ protein. One of its sulfonic acid groups is oriented toward the positive surface formed by the residues $\operatorname{Arg}^{100}, \mathrm{Arg}^{103}$, and $\mathrm{Arg}^{204}$, fulfilling the pharmacophore requirement HBA2 (Figure 2). The other sulfonic acid group, oriented to $\mathrm{Arg}^{132}$, is allocated far away from the $\mathrm{Arg}^{139}$ due to the absence of the HBA1 pharmacophore requirement.

Comparison between the UBQF14 DockDyn pose and the top ranked produced by Glide IFD (Figure $4 \mathrm{~b}$ ) reveals that they are clearly different, although the last one is closer to that obtained with DockDyn using phar31 as pharmacophore query. However, the RMSD cutoffs imposed in order to accept or discard poses generated by the DockDyn protocol prevented us from including this phar31derived pose in the set of solutions produced by this program.

Figure 5 shows the three poses obtained for the UBQF17 compound by means of the DockDyn program using phar4, phar32, and phar31 as pharmacophore queries. As can be seen, poses derived from phar4 and phar32 are very similar (Figures 5a and $b$ ), whereas major differences are observed for the phar31 derived pose (Figure 5c).

As has been previously commented, a total of 19 complexes formed by the $\mathrm{Bcl}-\mathrm{x}_{\mathrm{L}}$ protein and the best poses generated for the
UBQF14 and UBQF17 compounds by the DockDyn and Glide IFD programs were rescored using the MM-PBSA and MMGBSA approaches. For UBQF14, the best binding free energy value was obtained by either of these approaches for the complex formed by the $\mathrm{Bcl}-\mathrm{x}_{\mathrm{L}}$ protein and the top-ranked pose generated by the Glide IFD program. Similarly, both approaches coincided in identifying the complex formed by $\mathrm{Bcl}-\mathrm{x}_{\mathrm{L}}$ and the tenth energy-ranked pose of UBQF17 generated by Glide IFD as the most stable. These complexes, considered as the most probable binding modes of UBQF14 and UBQF 17 to $\mathrm{Bcl}-\mathrm{x}_{\mathrm{L}}$, are shown in Figures $4 \mathrm{c}$ and $5 \mathrm{~d}$.

Table 1 shows the contributions of the different energy terms to the MM-PBSA and MM-GBSA binding free energy. As can be seen, in both approaches, the electrostatic component of the solvation free energy makes the largest contribution to the binding of UBQF14 to $\mathrm{Bcl}-\mathrm{x}_{\mathrm{L}}$. Conversely, the binding of UBQF17 to this protein is clearly dominated by the van der Waals interaction. Moreover, for both compounds, the electrostatic term is unfavorable, whereas the nonpolar solvation term contributes only slightly favorably to the binding.

In a further step, MM-GBSA decomposition approach of these complexes was performed in order to identify residues of the Bcl$\mathrm{x}_{\mathrm{L}}$ protein that make significant contributions to the binding free energy associated to the complex formation (hot spot). In the present work, it was considered as a hot spot if any residue contributes more than $1.0 \mathrm{kcal} / \mathrm{mol}$ to the binding free energy of the complex.

Figure 6 shows the residues of $\mathrm{Bcl}-\mathrm{x}_{\mathrm{L}}$ found to make a significant contribution to ligand binding. In both complexes, residues of the protein that have the largest contribution to ligand binding are the arginine residues lining the binding site. However, their contribution varies from one complex to the other one. In the $\mathrm{Bcl}-\mathrm{x}_{\mathrm{L}} /$ UBQF14 complex, $\operatorname{Arg}^{139}$ (located at the HBA1 zone) and Arg ${ }^{100}$ 
(located at the HBA2 zone) are the most contributing residues to the binding free energy of the complex. In contrast, their contribution to the UBQF17 binding is lower compared to that observed for the residues $\mathrm{Arg}^{100}, \mathrm{Arg}^{103}, \mathrm{Arg}^{204}$ (located at the HBA2 zone), and $\mathrm{Arg}^{209}$.

With respect to the hydrophobic interactions, all residues with significant contribution to the free binding energy belong to one of the four hydrophobic pockets (referred to as h1-h4) located on the binding site surface of the Bcl- $x_{\mathrm{L}}$ protein. Specifically, UBQF14 spans over h2 (residues Phe ${ }^{105}$ and Leu ${ }^{130}$ ), h3 (including residues Phe ${ }^{97}$, $\mathrm{Arg}^{100}, \mathrm{Tyr}^{101}$, and $\mathrm{Ala}^{142}$ ), and $\mathrm{h} 4$ (residue $\mathrm{Tyr}^{195}$ ) pockets. In contrast, UBQF17 only occupies h2 (with residues Leu ${ }^{130}$ and $\mathrm{Phe}^{146}$ ) and h3 (residues $\mathrm{Phe}^{97}, \mathrm{Arg}^{100}, \mathrm{Tyr}^{101}$, and $\mathrm{Ala}^{142}$ ) pockets.

Finally, it is interesting to stress that the two compounds show similar binding patterns than the $\mathrm{BH} 3$ domains to anti-apoptotic proteins, ${ }^{35}$ although in this case, only three of the four hydrophobic sites are occupied by each antagonist due to their reduced size in comparison with $\mathrm{BH} 3$ peptides. This suggests that any modification of these compounds oriented to fill the unoccupied pocket could improve the affinity of these compounds for Bcl- $\mathrm{x}_{\mathrm{L}}$.

All necessary structures to reproduce Figures 2, 4, and 5 (obtained using the software Pymol version 0.99rc6) are provided as pdb files in the Supporting Information.

\section{CONCLUSIONS}

In the present work, a pharmacophore-based strategy was used for the discovery of small molecule antagonists of the anti-apoptotic protein $\mathrm{Bcl}-\mathrm{x}_{\mathrm{L}}$. The pharmacophore was derived from $\mathrm{MD}$ studies of the $\mathrm{Bcl}-\mathrm{x}_{\mathrm{L}} / \mathrm{X}(16 \mathrm{BH} 3)$ complexes, were $\mathrm{X}$ represents a $\mathrm{BH} 3$ hexadecapeptide of the pro-apoptotic proteins Bak, Bax, Bid, and Hrk and was not only used for virtual screening but also for site-directed docking. This strategy allowed the identification of 29 hits as Bcl- $x_{\mathrm{L}}$ antagonist candidates. Fifteen of them were acquired and assayed to assess their ability to disrupt the $\mathrm{Bcl}-\mathrm{x}_{\mathrm{L}} / \mathrm{Bak}(\mathrm{BH} 3)$ complex. Two of these compounds, UBQF14 and UBQF17, were able to avoid the $\mathrm{Bcl}-\mathrm{x}_{\mathrm{L}} / \mathrm{Bak}(\mathrm{BH} 3)$ interaction in vitro at the micromolar range. In order to characterize their binding mode, docking studies were performed. MD simulations followed by MM-PBSA and MM-GBSA binding free energy calculations were used as tools to refine and

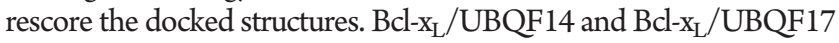
complexes having the best binding free energy values were chosen as those containing the most probable binding mode of these compounds. In order to indentify which residues of the Bcl- $\mathrm{x}_{\mathrm{L}}$ protein make the largest contribution to their binding, a MM-GBSA decomposition approach was performed on each one of the two obtained complexes. Hot spots reported by previous studies analyzing $\mathrm{Bcl}-\mathrm{x}_{\mathrm{L}} / \mathrm{BH}$-only protein complexes completely agree with those found in the MM-GBSA analysis. Taken together, these results clearly demonstrate the success of the strategy developed in the present work as a tool for drug discovery, appearing as a less-expensive and reliable alternative to high-throughput experimental screening.

\section{ASSOCIATED CONTENT}

S Supporting Information. PDB files of Figures 2, 4, and 5. This material is available free of charge via the Internet at http://pubs.acs.org.

\section{AUTHOR INFORMATION}

\section{Corresponding Author}

*E-mail: jaime.rubio@ub.edu. Telephone: +34 934039263.

\section{ACKNOWLEDGMENT}

We like to express our gratitude to the NCI for providing us samples of some of the compounds studied in the present work. This research was supported by the Spanish DGICYT (SAF200804943-C02-01, CTQ2006-06588/BQU and BIO2007-60066). This work was also supported in part by the Generalitat de Catalunya through project 2009SGR1308.

\section{REFERENCES}

(1) Thompson, C. B. Apoptosis in the pathogenesis and treatment of disease. Science 1995, 267, 1456-1462.

(2) Hanahan, D.; Weinberg, R. A. The hallmarks of cancer. Cell 2000, 100, 57-70.

(3) Grütter, M. G. Caspases: key players in programmed cell death. Curr. Opin. Struct. Biol. 2000, 10, 649-655.

(4) Yin, X. M. Signal transduction mediated by Bid, a pro-death Bcl-2 family proteins, connects the death receptor and mitochondria apoptosis pathways. Cell Res. 2000, 10, 161-167.

(5) Zimmermann, K. C.; Bonzon, C.; Green, D. R. The machinery of programmed cell death. Pharmacol. Ther. 2001, 92, 57-70.

(6) Chao, D. T.; Korsmeyer, S. J. Bcl-2 family: regulators of cell death. Annu. Rev. Immunol. 1998, 16, 395-419.

(7) Adams, J. M.; Cory, S. The Bcl-2 protein family: arbiters of cell survival. Science 1998, 281, 1322-1326.

(8) Reed, J. C. Bcl-2 family proteins. Oncogene 1998, 17, 3225-3236.

(9) Kuwana, T.; Newmeyer, D. D. Bcl-2-family proteins and the role of mitochondria in apoptosis. Curr. Opin. Cell Biol. 2003, 15, 691-696.

(10) Youle, R. J.; Strasser, A. The Bcl-2 protein family: opposing activities that mediate cell death. Nat. Rev. Mol. Cell Biol. 2008, 9, 47-59.

(11) Sattler, M.; Liang, H.; Nettesheim, D.; Meadows, R. P.; Harlan, J. E.; Eberstadt, M.; Yoon, H. S.; Shuker, S. B.; Chang, B. S.; Minn, A. J.; Thompson, C. B.; Fesik, S. W. Structure of Bcl-x $\mathrm{L}_{\mathrm{L}}$-Bak peptide complex: recognition between regulators of apoptosis. Science 1997, 275, 983-986.

(12) Liu, X.; Dai, S.; Zhu, Y.; Marrack, P.; Kappler, J. W. The structure of a Bcl- $\mathrm{x}_{\mathrm{L}} / \mathrm{Bim}$ fragment complex: implications for Bim function. Immunity 2003, 19, 341-352.

(13) Petros, A. M.; Nettesheim, D. G.; Wang, Y.; Olejniczak, E. T.; Meadows, R. P.; Mack, J.; Swift, K.; Matayoshi, E. D.; Zhang, H.; Thompson, C. B.; Fesik, S. W. Rationale for Bcl- $\mathrm{x}_{\mathrm{L}} / \mathrm{Bad}$ peptide complex formation from structure, mutagenesis, and biophysical studies. Protein Sci. 2000, 9, 2528-2534.

(14) Oberstein, A.; Jeffrey, P. D.; Shi, Y. Crystal structure of the Bcl$\mathrm{x}_{\mathrm{L}}$-Beclin 1 peptide complex: Beclin 1 is a novel $\mathrm{BH} 3$-only protein. J. Biol. Chem. 2007, 282, 13123-13132.

(15) Cosulich, S. C.; Worrall, V.; Hedge, P. J.; Green, S.; Clarke, P. R. Regulation of apoptosis by BH3 domains in a cell-free system. Curr. Biol. 1997, 7, 913-920.

(16) Holinger, E. P.; Chittenden, T.; Lutz, R. J. Bak BH3 peptides antagonize $\mathrm{Bcl}-\mathrm{x}_{\mathrm{L}}$ function and induce apoptosis through cytochrome c-independent activation of caspases. J. Biol. Chem. 1999, 274, 1329813304.

(17) Wang, J. L.; Liu, D.; Zhang, Z. J.; Shan, S.; Han, X.; Srinivasula, S. M.; Croce, C. M.; Alnemri, E. S.; Huang, Z. Structure-based discovery of an organic compound that binds $\mathrm{Bcl}-2$ protein and induces apoptosis of tumor cells. Proc. Natl. Acad. Sci. U.S.A. 2000, 97, 7124-7129.

(18) Brewis, N. D.; Phelan, A.; Normand, N.; Choolun, E.; O’Hare, P. Particle assembly incorporating a VP22-BH3 fusion protein, facilitating intracellular delivery, regulated release, and apoptosis. Mol. Ther. 2003, 7, 262-270.

(19) Goldsmith, K. C.; Liu, X.; Dam, V.; Morgan, B. T.; Shabbout, M.; Cnaan, A.; Letai, A.; Korsmeyer, S. J.; Hogarty, M. D. BH3 peptidomimetics potently activate apoptosis and demonstrate single agent efficacy in neuroblastoma. Oncogene 2006, 25, 4525-4533.

(20) Li, R.; Boehm, A. L.; Miranda, M. B.; Shangary, S.; Grandis, J. R.; Johnson, D. E. Targeting anti-apoptotic Bcl-2 family members with 
cell-permeable $\mathrm{BH} 3$ peptides induces apoptosis signaling and death in head and neck squamous cell carcinoma cells. Neoplasia 2007, 9, 801-811.

(21) Wang, J. L.; Zhang, Z. J.; Choksi, S.; Shan, S.; Lu, Z.; Croce, C. M.; Alnemri, E. S.; Korngold, R.; Huang, Z. Cell permeable Bcl-2 binding peptides: a chemical approach to apoptosis induction in tumor cells. Cancer Res. 2000, 60, 1498-1502.

(22) Tzung, S. P.; Kim, K. M.; Basañez, G.; Giedt, C. D.; Simon, J.; Zimmerberg, J.; Zhang, K. Y.; Hockenbery, D. M. Antimycin A mimics a cell-death-inducing Bcl-2 homology domain 3. Nat. Cell Biol. 2001, 3, 183-191.

(23) Enyedy, I. J.; Ling, Y.; Nacro, K.; Tomita, Y.; Wu, X.; Cao, Y.; Guo, R.; Li, B.; Zhu, X.; Huang, Y.; Long, Y. Q.; Roller, P. P.; Yang, D.; Wang, S. Discovery of small-molecule inhibitors of Bcl-2 through structure-based computer screening. J. Med. Chem. 2001, 44, 4313-4324.

(24) Degterev, A.; Lugovskoy, A.; Cardone, M.; Mulley, B.; Wagner, G.; Mitchison, T.; Yuan, J. Identification of small-molecule inhibitors of interaction between the BH3 domain and Bcl- $\mathrm{x}_{\mathrm{L}}$. Nat. Cell Biol. 2001, 3, 173-182.

(25) Becattini, B.; Kitada, S.; Leone, M.; Monosov, E.; Chandler, S.; Zhai, D.; Kipps, T. J.; Reed, J. C.; Pellecchia, M. Rational design and real time, in-cell detection of the proapoptotic activity of a novel compound targeting Bcl- $\mathrm{x}_{\mathrm{L}}$. Chem. Biol. 2004, 11, 389-395.

(26) Mohammad, R.; Young, D.; Chen, B.; Aboukameel, A.; Chen, J.; Nikolovska-Coleska, Z. ApoG2, a potent, non-toxic small-molecule inhibitor of Bcl-2 family: a preclinical trial in lymphoma. Proc. Amer. Assoc. Cancer Res. 2006, 47, Abstract 1335.

(27) Wang, G.; Nikolovska-Coleska, Z.; Yang, C. Y.; Wang, R.; Tang, G.; Guo, J.; Shangary, S.; Qiu, S.; Gao, W.; Yang, D.; Meagher, J.; Stuckey, J.; Krajewski, K.; Jiang, S.; Roller, P. P.; Abaan, H. O.; Tomita, Y.; Wang, S. Structure-based design of potent small-molecule inhibitors of anti-apoptotic Bcl-2 proteins. J. Med. Chem. 2006, 49, 6139-6142.

(28) Oltersdorf, T.; Elmore, S. W.; Shoemaker, A. R.; Armstrong, R. C.; Augeri, D. J.; Belli, B. A.; Bruncko, M.; Deckwerth, T. L.; Dinges, J.; Hajduk, P. J.; Joseph, M. K.; Kitada, S.; Korsmeyer, S. J.; Kunzer, A. R.; Letai, A.; Li, C.; Mitten, M. J.; Nettesheim, D. G.; Ng, S.; Nimmer, P. M.; O'Connor, J. M.; Oleksijew, A.; Petros, A. M.; Reed, J. C.; Shen, W.; Tahir, S. K.; Thompson, C. B.; Tomaselli, K. J.; Wang, B.; Wendt, M. D.; Zhang, H.; Fesik, S. W.; Rosenberg, S. H. An inhibitor of Bcl-2 family proteins induces regression of solid tumours. Nature 2005, 435, $677-681$.

(29) Wendt, M. D.; Shen, W.; Kunzer, A.; McClellan, W. J.; Bruncko, M.; Oost, T. K.; Ding, H.; Joseph, M. K.; Zhang, H.; Nimmer, P. M.; Ng, S. C.; Shoemaker, A. R.; Petros, A. M.; Oleksijew, A.; Marsh, K.; Bauch, J.; Oltersdorf, T.; Belli, B. A.; Martineau, D.; Fesik, S. W.; Rosenberg, S. H.; Elmore, S. W. Discovery and structure-activity relationship of antagonists of B-cell lymphoma 2 family proteins with chemopotentiation activity in vitro and in vivo. J. Med. Chem. 2006, 49, $1165-1181$.

(30) Shoemaker, A. R.; Oleksijew, A.; Bauch, J.; Belli, B. A.; Borre, T.; Bruncko, M.; Deckwirth, T.; Frost, D. J.; Jarvis, K.; Joseph, M. K.; Marsh, K.; McClellan, W.; Nellans, H.; Ng, S.; Nimmer, P.; O'Connor, J. M.; Oltersdorf, T.; Qing, W.; Shen, W.; Stavropoulos, J.; Tahir, S. K.; Wang, B.; Warner, R.; Zhang, H.; Fesik, S. W.; Rosenberg, S. H.; Elmore, S. W. A small-molecule inhibitor of Bcl- $\mathrm{x}_{\mathrm{L}}$ potentiates the activity of cytotoxic drugs in vitro and in vivo. Cancer Res. 2006, 66, 8731-8739.

(31) Kitada, S.; Leone, M.; Sareth, S.; Zhai, D.; Reed, J. C.; Pellecchia, M. Discovery, characterization, and structure-activity relationships studies of proapoptotic polyphenols targeting B-cell lymphocyte/leukemia-2 proteins. J. Med. Chem. 2003, 46, 4259-4264.

(32) Tse, C.; Shoemaker, A. R.; Adickes, J.; Anderson, M. G.; Chen, J.; Jin, S.; Johnson, E. F.; Marsh, K. C.; Mitten, M. J.; Nimmer, P.; Roberts, L.; Tahir, S. K.; Xiao, Y.; Yang, X.; Zhang, H.; Fesik, S.; Rosenberg, S. H.; Elmore, S. W. ABT-263: a potent and orally bioavailable Bcl-2 family inhibitor. Cancer Res. 2008, 68, 3421-3428.

(33) Lee, E. F.; Czabotar, P. E.; Smith, B. J.; Deshayes, K.; Zobel, K.; Colman, P. M.; Fairlie, W. D. Crystal structure of ABT-737 complexed with Bcl- $x_{\mathrm{L}}$ : implications for selectivity of antagonists of the Bcl-2 family. Cell Death Differ. 2007, 14, 1711-1713.

(34) Lugovskoy, A. A.; Degterev, A. I.; Fahmy, A. F.; Zhou, P.; Gross, J. D.; Yuan, J.; Wagner, G. A novel approach for characterizing protein ligand complexes: molecular basis for specificity of small-molecule Bcl-2 inhibitors. J. Am. Chem. Soc. 2002, 124, 1234-1240.

(35) Lama, D.; Sankararamakrishnan, R. Anti-apoptotic Bcl-XL protein in complex with $\mathrm{BH} 3$ peptides of pro-apoptotic Bak, Bad, and Bim proteins: comparative molecular dynamics simulations. Proteins 2008, 73, 492-514.

(36) Pinto, M.; Perez, J. J.; Rubio-Martinez, J. Molecular dynamics study of peptide segments of the $\mathrm{BH} 3$ domain of the proapoptotic proteins Bak, Bax, Bid and Hrk bound to the $\mathrm{Bcl}-\mathrm{x}_{\mathrm{L}}$ and $\mathrm{Bcl}-2$ proteins. J. Comput.-Aided Mol. Des. 2004, 18, 13-22.

(37) Friesner, R. A.; Banks, J. L.; Murphy, R. B.; Halgren, T. A.; Klicic, J. J.; Mainz, D. T.; Repasky, M. P.; Knoll, E. H.; Shelley, M.; Perry, J. K.; Shaw, D. E.; Francis, P.; Shenkin, P. S. Glide: a new approach for rapid, accurate docking and scoring. 1. Method and assessment of docking accuracy. J. Med. Chem. 2004, 47, 1739-1749.

(38) Maestro, version 8.5; Schrödinger: New York, 2009.

(39) Sherman, W.; Day, T.; Jacobson, M. P.; Friesner, R. A.; Farid, R. Novel procedure for modeling ligand/receptor induced fit effects. J. Med. Chem. 2006, 49, 534-553.

(40) Prime, version 1.6; Schrödinger: New York, 2009.

(41) Case, D. A.; Darden, T. A.; Cheatham, T. E., III; Simmerling, C. L.; Wang, J.; Duke, R. E.; Luo, R.; Merz, K. M.; Pearlman, D. A.; Crowley, M.; Walker, R. C.; Zhang, W.; Wang, B.; Hayik, S.; Roitberg, A.; Seabra, G.; Wong, K. F.; Paesani, F.; Wu, X.; Brozell, S.; Tsui, V.; Gohlke, H.; Yang, L.; Tan, C.; Mongan, J.; Hornak, V.; Cui, G.; Beroza, P.; Mathews, D. H.; Schafmeister, C.; Ross, W. S.; Kollman, P. A. AMBER 9; University of California, San Francisco: San Francisco, CA, 2006.

(42) Duan, Y.; Wu, C.; Chowdhury, S.; Lee, M. C.; Xiong, G.; Zhang, W.; Yang, R.; Cieplak, P.; Luo, R.; Lee, T. A point-charge force field for molecular mechanics simulations of proteins based on condensed-phase quantum mechanical calculations. J. Comput. Chem. 2003, 24, 1999-2012.

(43) Wang, J.; Wolf, R. M.; Caldwell, J. W.; Kollman, P. A.; Case, D. A. Development and testing of a general amber force field. J. Comput. Chem. 2004, 25, 1157-1174.

(44) Jorgensen, W. L.; Chandrasekhar, J.; Madura, J. D.; Impey, R. W.; Klein, M. L. Comparison of simple potential functions for simulating liquid water. J. Chem. Phys. 1983, 79, 926-935.

(45) Darden, T.; York, D.; Pedersen, L. Particle Mesh Ewald: An $\operatorname{Nlog}(\mathrm{N})$ method for Ewald sums in large systems. J. Chem. Phys. 1993, 98, 10089-10092.

(46) Berendsen, H. J. C.; Postman, J. P. M.; Van Gunsteren, W. F.; Di Nola, A.; Haak, J. R. Molecular dynamics with coupling to an external bath. J. Chem. Phys. 1984, 81, 3684-3690.

(47) Ryckaert, J. P.; Ciccotti, G.; Berendsen, H. J. Numerical integration of the cartesian equations of motion of a system with constraints: molecular dynamics of n-alkanes. J. Comput. Chem. 1977, 23, $327-341$.

(48) Kollman, P. A.; Massova, I.; Reyes, C.; Kuhn, B.; Huo, S.; Chong, L.; Lee, M.; Lee, T.; Duan, Y.; Wang, W.; Donini, O.; Srivasan, J.; Case, D. A.; Cheatam, T. E., III. Calculating structures and free energies of complex molecules: Combining molecular mechanics and continuum models. Acc. Chem. Res. 2000, 33, 889-897.

(49) Onufriev, A.; Bashford, D.; Case, D. A. Modification of the Generalized Born Model Suitable for Macromolecules. J. Phys. Chem. B 2000, 104, 3712-3720.

(50) Weiser, J.; Shemkin, P. S.; Still, W. C. Approximate atomic surfaces from linear combinations of pairwise overlaps (LCPO). J. Comput. Chem. 1999, 20, 217-230.

(51) Gohlke, H.; Kiel, C.; Case, D. A. Insights into protein-protein binding by binding free energy calculation and free energy decomposition for the Ras-Raf and Ras-RalGDS complexes. J. Mol. Biol. 2003, 330, 891-913. 
(52) Zhang, H.; Nimmer, P.; Rosenberg, S. H.; Ng, S. C.; Joseph, M. Development of a high-throughput fluorescence polarization assay for Bcl- $\mathrm{x}_{\mathrm{L}}$. Anal. Biochem. 2002, 307, 70-75.

(53) Orzáez, M.; Mondragón, L.; García-Jareño, A.; Mosulén, S.; Pineda-Lucena, A.; Pérez-Payá, E. Decipering the antitumoral activity of quinacrine: Binding to and inhibition of $\mathrm{Bcl}-\mathrm{x}_{\mathrm{L}}$. Bioorg. Med. Chem. Lett. 2009, 19, 1592-1595.

(54) Mukherjee, P.; Desai, P.; Zhou, Y. D.; Avery, M. Targeting the $\mathrm{BH} 3$ domain mediated protein-protein interaction of $\mathrm{Bcl}-\mathrm{x}_{\mathrm{L}}$ through Virtual Screening. J. Chem. Inf. Model. 2010, 50, 906-923.

(55) Seidler, J.; McGover, S. L.; Doma, T. N.; Schoichet, B. K. Identification and prediction of promiscuous aggregating inhibitors among known drugs. J. Med. Chem. 2003, 46, 4477-4486. 